\title{
Influence of morphology on high-temperature rheological properties of bitumen modified with styrene-butadiene-styrene (SBS) copolymer
}

\author{
Jiqing $\mathbf{Z H U}^{\mathbf{a}^{*}}$, Xiaohu $\mathbf{L U}^{\mathrm{b}}$ \\ ${ }^{a}$ Swedish National Road and Transport Research Institute (VTI), Linköping SE-581 95, Sweden \\ ${ }^{b}$ Nynas AB, Nynäshamn SE-149 82, Sweden \\ *Corresponding author. E-mail: jiqing.zhu@vti.se
}

(C) The Author(s) 2021. This article is published with open access at link.springer.com and journal.hep.com.cn 2021

\begin{abstract}
Different microstructures of the same polymer-modified bitumen (PMB) were obtained by subjecting the bitumen modified with styrene-butadiene-styrene (SBS) copolymer to isothermal annealing at various temperatures. The effects of the morphology on the rheological properties of SBS-modified bitumen were investigated within the hightemperature range. The PMB microstructures were quantitatively evaluated using image analysis. A dynamic shear rheometer was used to measure the rheological parameters of the PMB samples and perform the multiple stress creep and recovery (MSCR) test. A quantitative basis could be established on which to discuss the relationship between the PMB morphology and rheology. The image analysis indicated that conditioning by isothermal annealing evidently led to a difference in the microstructure of the samples. Variation of the thermal history is demonstrated to be a practical way to vary the morphology of the PMB with the same raw materials and formulation. Compared with the two-phase morphology, the single-phase microstructure tended to have a narrower linear viscoelastic (LVE) region of the PMB. Within the LVE region, especially at low frequencies, the homogenous PMB can store more energy when experiencing loadings and is more elastic. Outside the LVE region, based on the MSCR test results, the homogenous morphology could assist in reaching a higher percentage of strain recovery after the creep period.
\end{abstract}

KEYWORDS polymer, bitumen, microstructure, rheology, viscoelasticity

\section{Introduction}

The modification of bitumen with synthetic polymers for paving applications is a globally popular practice. This modification helps to improve certain engineering properties of bituminous binders, for example, the rheological properties [1,2]. An important and critical research topic regarding polymer-modified bitumen (PMB), to ensure its high performance, is the relationship between the PMB microstructure and its rheological properties. This is further related to another fundamental research question, that is, the way in which the morphology of PMB originates under various conditions. These topics have been studied intensively by researchers throughout the years [3-11]. It is well accepted that the mixing of polymer

Article history: Received Sep 25, 2019; Accepted Mar 2, 2021 modifiers with bitumen is a complex process that usually includes the dispersion and swelling of the modifier and phase evolution of the blend. The physical and chemical nature and content of the modifier, the crude oil source of the bitumen, and processing conditions for the mixing are the main factors that can affect the morphology of modified bitumen [12-16].

In addition to the microstructure, the rheological properties of the raw materials (the base bitumen and pure polymer) also have a great influence on the rheology of the final PMB. The composition and properties of bitumen are known to vary significantly from one source of crude oil to another. The chemical composition, molecular structure, and rheology of the pure polymers can vary as well. These variations usually influence the microstructure of the PMB and rheology of the raw material simultaneously. In other words, a change in the raw material (base 
bitumen or polymer) used for PMB often changes both the polymer-bitumen compatibility and rheology of the raw material at the same time, leading to a different PMB with different morphology and rheology. From a fundamental point of view, however, it is necessary and of great importance to separately investigate the influence of the morphology of PMB and rheology of the raw material on the final PMB, ideally with one varying factor and all others fixed for each investigation. This may assist in increasing our understanding of PMB materials and thus help to quickly determine the possible industrial solutions and develop new solutions.

Many previous studies $[1-3,5,7,10,14]$ were devoted to investigating the rheological properties of PMBs with the same types of raw materials but varying polymer contents. Based on the different PMB formulations, these studies revealed the compositional influence of PMB morphology on its rheology. Nevertheless, the structural effect of the morphology of PMB based on the same material composition was not addressed. To study the structural effect of the morphology of PMB on its rheology, previous studies used additives such as sulfur and carbon nanotubes $[17,18]$. These additives helped to obtain different PMB microstructural patterns with the same raw materials and formulations. The changes in the rheology of the PMB were then investigated. However, the use of additives, in this case, increases the system complexity and may lead to unknown influencing factors in the research question. Therefore, avoiding the use of additives to obtain PMB with various microstructures is preferable. Without additives, a possible approach for obtaining PMB with different microstructures based on the same material composition would be to control the material processing. Soenen et al. [19-22] concluded that the thermal history can have a considerable influence on the morphology of PMB samples and thus can affect the measurement results of rheological properties, especially when the applied loading frequency is low. A similar effect was also observed for other types of modified bitumen, for example, wax-modified bitumen, because of the formation of its microcrystalline network structure [23]. This might have provided a potential way to vary the morphology of PMB with the same raw materials and formulation, that is, to vary the thermal history.

To verify this new angle for examining the morphologyrheology relationship of PMB and to gain new insights from it, in the present study, a bituminous binder modified with styrene-butadiene-styrene (SBS) copolymer was subjected to isothermal annealing at various temperature levels. The aim thereof was to obtain different microstructures of the same PMB. The obtained microstructures were then observed with a fluorescence microscope and evaluated by image analysis using the two-dimensional fast Fourier transform (2D-FFT) method. In terms of the rheology, the focus was placed on the high-temperature range where the PMB rheology tends to be more sensitive to the morphology. A dynamic shear rheometer (DSR) was used to measure the linear viscoelastic (LVE) region limits, complex modulus $\left(G^{*}\right)$, phase angle $(\delta)$ at high temperatures, and low shear viscosity (LSV) of the PMB samples with different microstructures. In addition, multiple stress creep and recovery (MSCR) tests were conducted to analyze and compare the samples. Within the hightemperature range, the influence of the microstructure on the rheology of PMB is discussed based on the tests and an analysis of the results.

\section{Materials and method}

\subsection{Materials}

A 70/100 penetration grade (paving grade) base bitumen was used to prepare the PMB that was analyzed in this study. The saturates, aromatics, resins, and asphaltenes (SARA) fractions of this base bitumen were measured by thin-layer chromatography with flame ionization detection (TLC-FID). The needle penetration (in $0.1 \mathrm{~mm}$, i.e., dmm) was tested at $25^{\circ} \mathrm{C}$ with a $100 \mathrm{~g}$ load for a period of $5 \mathrm{~s}$. The softening point was tested using the ring and ball method, and the penetration index was calculated according to a published method [24]. The test results are presented in Fig. 1.

For the preparation of PMB, a low-shear mixer was used to blend a linear-type SBS copolymer with $70 / 100$ base bitumen at approximately $500 \mathrm{r} / \mathrm{min}$. The properties of the SBS copolymer are presented in Fig. 1. The polymer content of the PMB was $5 \%$ by weight of the blend. The mixing temperature was $180^{\circ} \mathrm{C}$, and the mixing duration was $3 \mathrm{~h}$. After the preparation, the basic PMB properties were assessed, including needle penetration (in $0.1 \mathrm{~mm}$, i.e., $\mathrm{dmm}$ ) at $25^{\circ} \mathrm{C}$, the ring and ball softening point, and the penetration index. This PMB was also tested for its storage stability by conducting the tube test (hot storage at $180^{\circ} \mathrm{C}$ for $72 \mathrm{~h}$ ), and the results indicated that it is sufficiently stable for the purpose of storage. The measurement results are presented in Fig. 1.

\subsection{Method}

\subsubsection{Isothermal annealing of PMB}

Figure 2 presents an overview of the experimental procedures used in this study. To control the morphology, the prepared PMB was conditioned by isothermal annealing for $1 \mathrm{~h}$ after each sampling (before the start of each test). The two annealing temperatures that were selected, $160^{\circ} \mathrm{C}$ and $120^{\circ} \mathrm{C}$, were expected to result in two different PMB microstructures for further tests, named ITA160 and ITA120, respectively, according to the annealing temperature. The selection of the temperatures and duration of the 


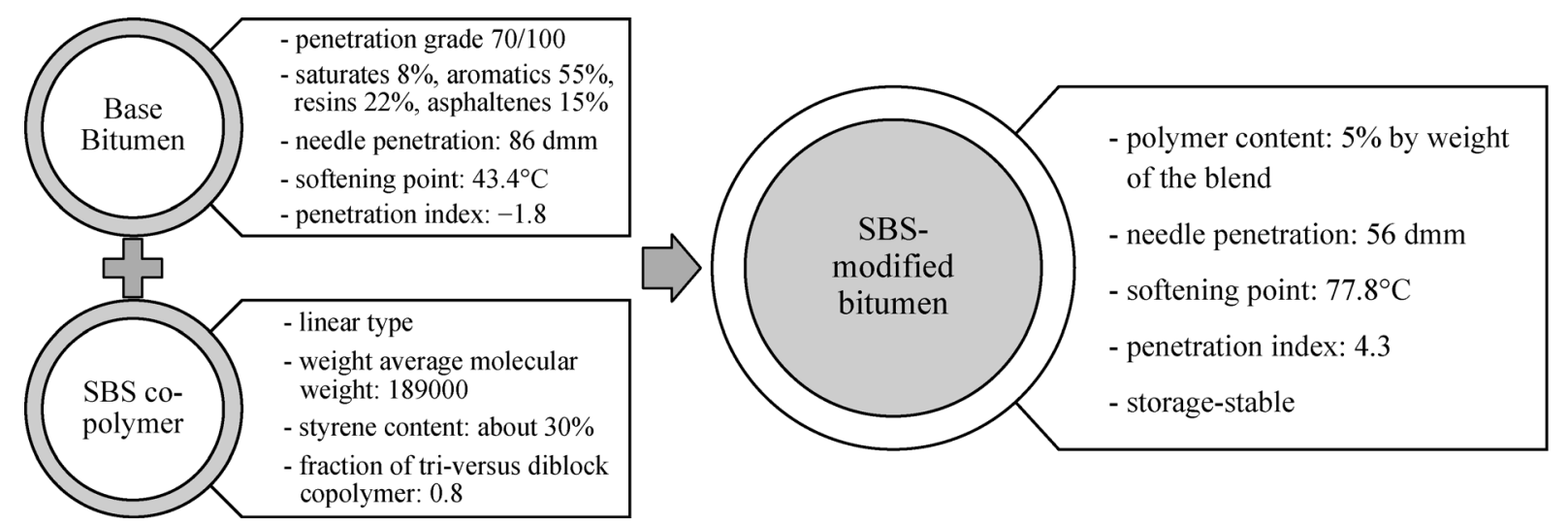

Fig. 1 Properties of the base bitumen and SBS copolymer used, and PMB prepared in this study.

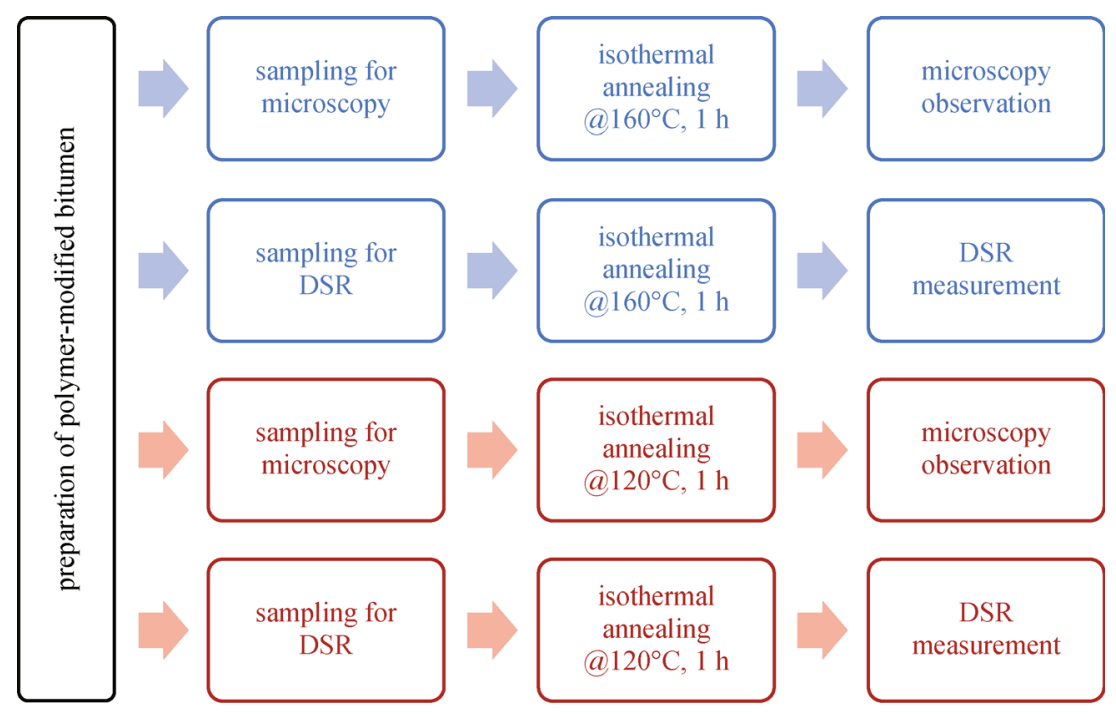

Fig. 2 Overview of the experimental procedures.

annealing processes in this study aims to achieve a balance between obtaining microstructures that differ significantly and avoiding extensive aging of the samples. It is worth mentioning that both temperatures are within the range of annealing temperatures allowed by the standard test method ASTM D7175 for measuring the rheological properties of bituminous binders (below $163^{\circ} \mathrm{C}$ ).

Samples for microscopic observation were prepared by using the "thin film method" [16,21]. This method is suitable for evaluating the miscibility of a polymerbitumen combination and provides a representative morphology of the blend at the temperature of interest. PMB drops were collected at $200^{\circ} \mathrm{C}$ to ensure a miscible state at the beginning of the annealing process. The drops were spread on glass slides with coverslips to prepare the thin-film samples. These thin films were then reheated to their respective annealing temperatures and maintained at those temperatures for $1 \mathrm{~h}$. The slides were quickly cooled to room temperature for further observation.

DSR measurements were conducted by using a plate- plate geometry of $25 \mathrm{~mm}$ in diameter with a $1 \mathrm{~mm}$ gap for all the tests in this study. To prepare the samples for DSR measurements, $0.532 \mathrm{~g}( \pm 0.010 \mathrm{~g})$ of PMB was weighed at room temperature and melted at $200^{\circ} \mathrm{C}$ in a silicone mold. This is the same temperature at which the samples for microscopic observation were collected to ensure the same miscible state at the beginning of the annealing process. After that, the melted DSR samples were maintained in the molds at their respective annealing temperatures for $1 \mathrm{~h}$. During this process, the samples in the molds were covered with a clean penetration test container to minimize the effects of thermal oxidation. Finally, the annealed samples were placed in a refrigerator at $5^{\circ} \mathrm{C}$ for fast cooling and demolding, after which the samples were immediately subjected to DSR testing.

\subsubsection{Microscopy observation and image analysis}

A Carl Zeiss Axioskop 40 FL fluorescence microscope was used to observe the microstructure of the PMB samples 
from the prepared microscopic slides. The 2D-FFT method [15] was employed to analyze the captured images. Under the fluorescence microscope, the SBS-rich phase appears much lighter than the bitumen-rich phase. Thus, microstructural information of the PMB can be extracted from a microscopy image by characterizing the pattern of the phase distribution. With image analysis using 2D-FFT, the PMB morphology can be evaluated with the aid of quantitative parameters such as the characteristic spatial frequency and characteristic wavelength.

The principle of the 2D-FFT method $[25,26]$ can be described as follows: let $f\left(r_{1}, r_{2}\right)$ represent the PMB phase distribution in a microscopy image, where $\left(r_{1}, r_{2}\right)$ is the positional coordinate in the real $2 \mathrm{D}$ space. The power spectra $P\left(k_{1}, k_{2}\right)$ of the microscopy image in the spatial frequency domain are expressed as

$$
P\left(k_{1}, k_{2}\right)=\left|F\left(k_{1}, k_{2}\right)\right|^{2},
$$

where $F\left(k_{1}, k_{2}\right)$ is the Fourier transform $(\mathrm{FT})$ of $f\left(r_{1}, r_{2}\right)$. For a microscopy image of $N \times N$ pixels, the discrete Fourier transform (DFT) gives

$$
F\left(k_{1}, k_{2}\right)=\frac{1}{N} \sum_{r_{1}=0}^{N-1} \sum_{r_{2}=0}^{N-1} f\left(r_{1}, r_{2}\right) \mathrm{e}^{-j \frac{2 \pi}{N}\left(k_{1} r_{1}+k_{2} r_{2}\right)} .
$$

FFT algorithms can be used to quickly solve the DFT. A 2D-FFT algorithm with ImageJ [27] was adopted in the present study to analyze the PMB microscopy images, with the spatial frequency $k$ defined as

$$
k=\sqrt{k_{1}^{2}+k_{2}^{2}} .
$$

To characterize the PMB morphology, the light intensity of the power spectrum was normalized, and its radial distribution was plotted against the spatial frequency $k$. In the case in which a peak appears in the distribution, the spatial frequency corresponding to the peak is defined as the characteristic spatial frequency $k_{\mathrm{m}}$ of the PMB microstructure. Furthermore, the characteristic wavelength $\xi$ (angular wavelength) of the microstructure is calculated as

$$
\xi=\frac{2 \pi}{k_{\mathrm{m}}} .
$$

This wavelength represents the spatial length of $2 \pi$ periods of the characteristic microstructure.

\subsubsection{Rheological characterization}

A Bohlin DSR II rheometer was used to conduct the DSR measurements in this study, with a total water immersion system to control the temperature. The first step was to determine the limits of the LVE region of ITA160 and ITA120. Strain sweeps were carried out at $64^{\circ} \mathrm{C}$ and 10 $\mathrm{rad} / \mathrm{s}$ until the measured $G^{*}$ decreased significantly. The test temperature and frequency levels were the lowest temperature and highest frequency of the subsequent $G^{*}$ and $\delta$ measurements, which are usually the limiting conditions for the selection of strain level in practice [28]. Thus, it could provide a basis for ensuring the DSR measurements within the LVE region. The $G^{*}$ and $\delta$ values of ITA 160 and ITA120 were further measured in accordance with the standard test method ASTM D7175 at $64^{\circ} \mathrm{C}, 70^{\circ} \mathrm{C}, 76^{\circ} \mathrm{C}$, and $82^{\circ} \mathrm{C}$, and at 10,1 , and $0.1 \mathrm{rad} / \mathrm{s}$ at each temperature level. It is worth noting that each DSR measurement was obtained by averaging the data for 10 loading cycles. Two repetitions were performed at $10 \mathrm{rad} / \mathrm{s}$ (each temperature level) to ensure that the repeatability of the testing instrument and procedure was acceptable according to the standard.

Additionally, the LSV values of ITA160 and ITA120 were measured at $60^{\circ} \mathrm{C}, 70^{\circ} \mathrm{C}$, and $80^{\circ} \mathrm{C}$. These measurements were carried out by conducting frequency sweep tests from $0.1 \mathrm{rad} / \mathrm{s}$ to approximately $100 \mathrm{rad} / \mathrm{s}$ with an input strain level of $0.005(0.5 \%)$. The obtained complex viscosity $\left(\eta^{*}\right)$ results were then fitted with the Cross model and extrapolated at a relatively low frequency, which is defined as the LSV value [29-31]. Furthermore, MSCR tests were conducted on both ITA 160 and ITA 120 at $76^{\circ} \mathrm{C}$, $70^{\circ} \mathrm{C}$, and $64^{\circ} \mathrm{C}$, in line with the standard test method ASTM D7405 (version 10a). The standard MSCR test consists of ten repetitive creep-recovery cycles, and two repetitions were performed at $70^{\circ} \mathrm{C}$ for both ITA 160 and ITA120 to verify the measurement repeatability and ensure acceptable results according to the standard.

\section{Results and discussion}

\subsection{PMB morphology}

The images of the microstructures captured by fluorescence microscopy are shown in Fig. 3 on the left. The images reveal that ITA160 presents a homogenous microstructure (Fig. 3(a)) whereas ITA120 displays a binary pattern of droplets (rich in SBS) in the matrix (rich in bitumen) as shown in Fig. 3(b). Lu et al. [32] reported additional details on the morphological analysis. This result implies that variation of the annealing temperature indeed changed the thermodynamic stability of the PMB from the stable ITA160 to the unstable ITA120, probably because of the existence of an upper critical solution temperature (UCST) for the system [21,33].

The 2D-FFT power spectra of the captured images are shown in Fig. 3 on the right (color 3D plots for improved visual clarity), with the original greyscale results in the middle. In Fig. 3(a), the power spectrum of ITA160 contains a very well resolved peak, indicating the fast decay of light intensity with increasing spatial frequency. In comparison, ITA120 displays a rather poorly resolved broad bump, as shown in Fig. 3(b). This shows the 

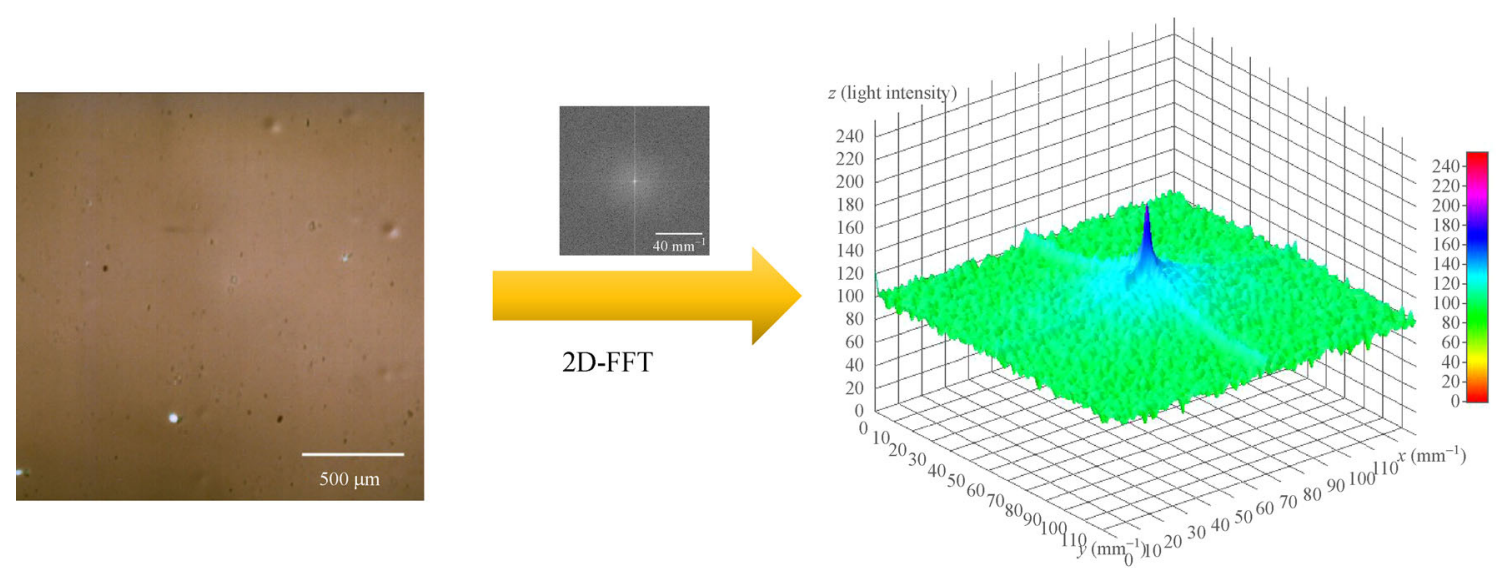

(a)
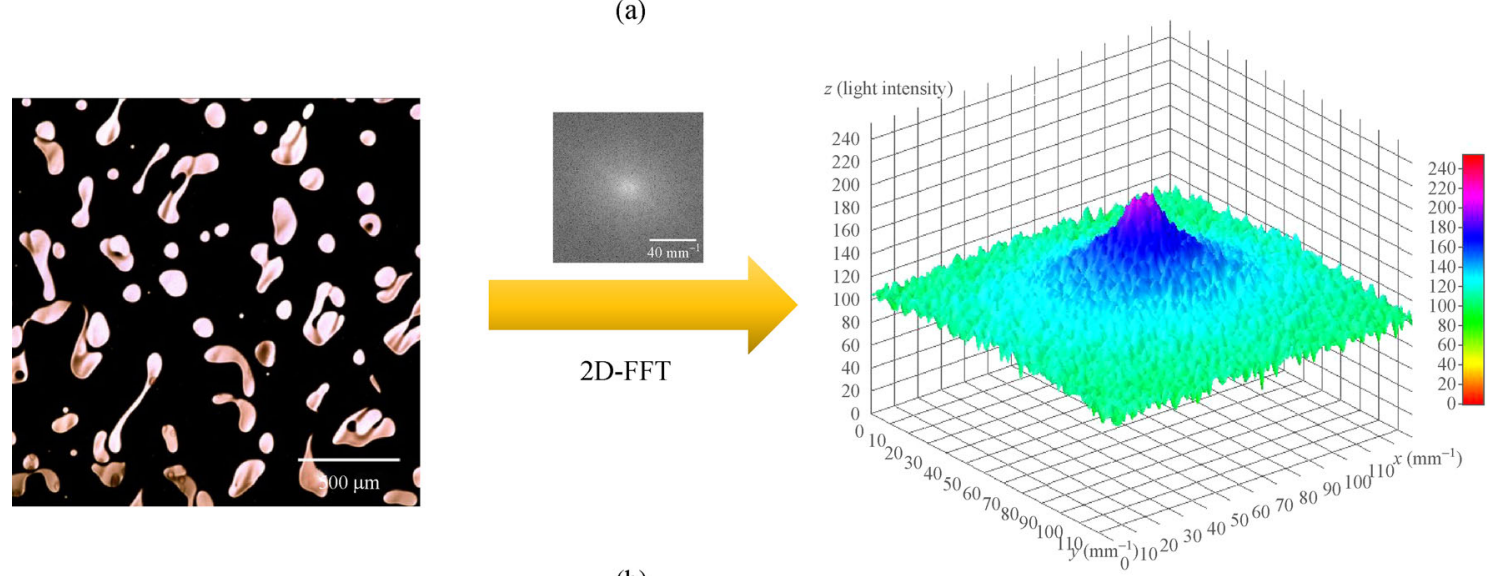

(b)

Fig. 3 Images of the PMB morphology (left) and 2D-FFT power spectra (right): (a) ITA160; (b) ITA120.

possibility of a periodic structural pattern existing in ITA120.

The radial distribution of the normalized light intensity in the power spectrum is plotted against the spatial frequency $k$, as shown in Fig. 4. The distribution curve of ITA160 decays with increasing spatial frequency. However, ITA120 exhibits a broad peak on its curve. For ITA160, the decay curve reveals the lack of a periodic

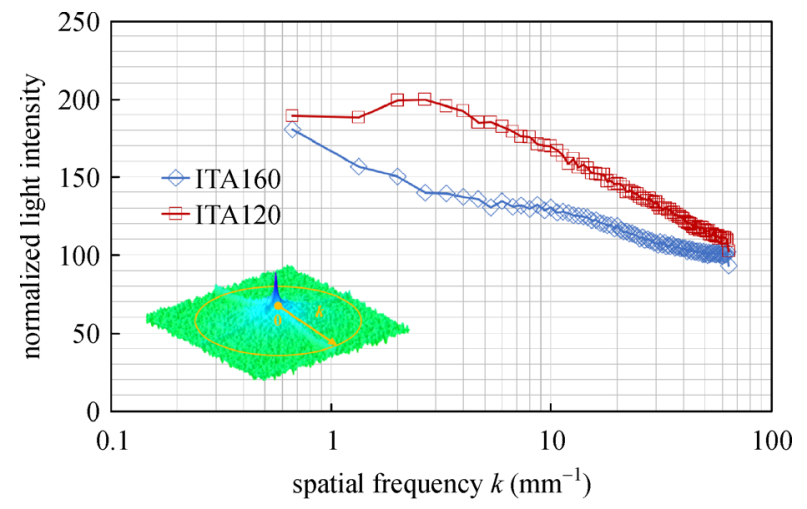

Fig. 4 Radial distribution of normalized light intensity in the 2DFFT power spectra. pattern in its microstructure. However, the dominant spatial frequency for ITA120 indicates the existence of significant periodicity.

To quantify this, the characteristic wavelength, $\xi$, was computed using Eq. (4) from the microscopic images of each PMB microstructure. For ITA160, no peak is presented on its curve, and $k_{\mathrm{m}}$ can be considered infinite. According to Eq. (4), the $\xi$ value of ITA160 was $0 \mathrm{~mm}$. For ITA120, however, the peak on its curve leads to a characteristic wavelength of $2.356 \mathrm{~mm}$. This confirms that the conditioning by isothermal annealing at $160^{\circ} \mathrm{C}$ and $120^{\circ} \mathrm{C}$ evidently resulted in a difference in the PMB microstructure. Further testing of these PMB samples of different microstructures with the same material composition may reveal the influence of morphology on PMB properties.

\subsection{Linear viscoelastic region}

The determination of the limits of the LVE region of ITA 160 and ITA 120 is necessary for two purposes in this study: 1) to ensure that subsequent $G^{*}$ and $\delta$ measurements are within the LVE region, and 2) to study the influence of the PMB microstructure on the range of its LVE region. 
Based on the strain sweep results shown in Fig. 5, the strain limits were determined at the points where the decrease in $G^{*}$ reached $5 \%$ of the initial value $G_{0}^{*}$ (the other $95 \%$ remains) according to $[34,35]$. The results in Fig. 5 indicate that $G_{0}^{*}$ of both ITA160 and ITA120 was slightly higher than $5000 \mathrm{~Pa}$. This reveals that the morphological difference between samples in the LVE region did not significantly affect the $G^{*}$ value at $64^{\circ} \mathrm{C}$ and $10 \mathrm{rad} / \mathrm{s}$. However, the limits of the LVE region were affected.

Figure 6 illustrates the determination of the limits of the LVE region for ITA 160 and ITA 120 by interpolation. The ITA160 curve represents the average result of two duplicate measurements, whereas the ITA120 curve is based on a single determination (similar uncertainty as
ITA160). This indicates that ITA160 reached its limit at a lower strain level than ITA120. The strain limits were 0.778 and 0.983 for the two samples, respectively. According to previous studies by Airey et al. [36,37], SBS-modified bitumen tends to present a reduced strain limit at high temperatures when the elastomeric polymer forms a dominant matrix. This could explain the narrowing of the LVE region of ITA160 with a homogenous microstructure. The determined strain limits for the two samples were within the proposed range of 0.500 to 2.00 for SBS-modified bitumen at high temperatures [38]. This reduction in the strain limit can be an indication of a higher degree of polymer-bitumen interaction in ITA160 than in ITA120.

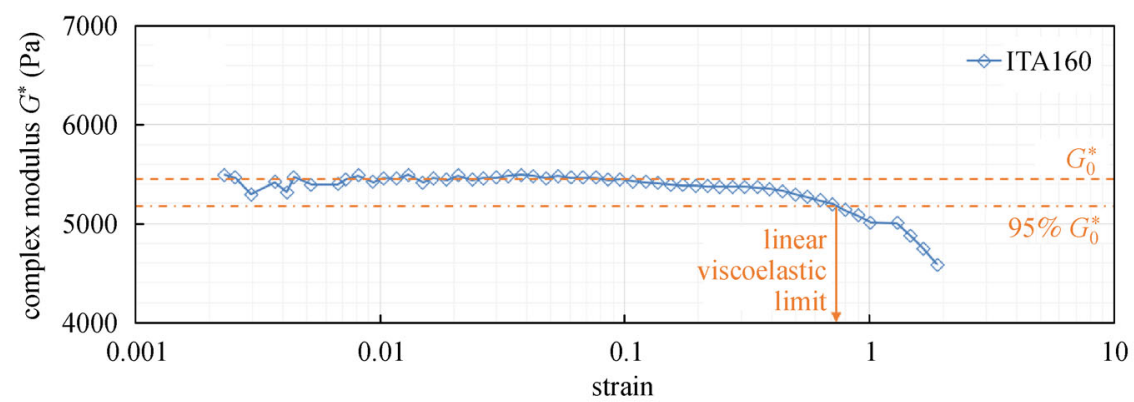

(a)

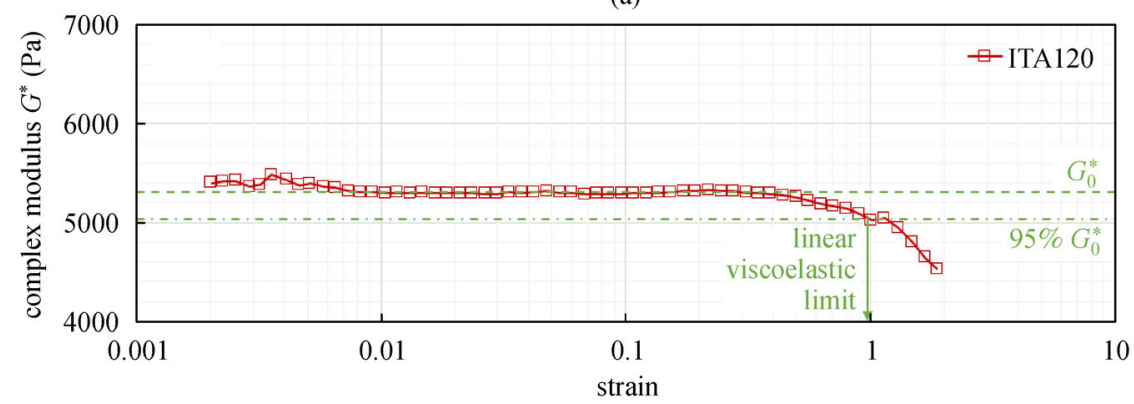

(b)

Fig. 5 Strain sweep at $64^{\circ} \mathrm{C}$ and $10 \mathrm{rad} / \mathrm{s}$ : (a) ITA160; (b) ITA120.

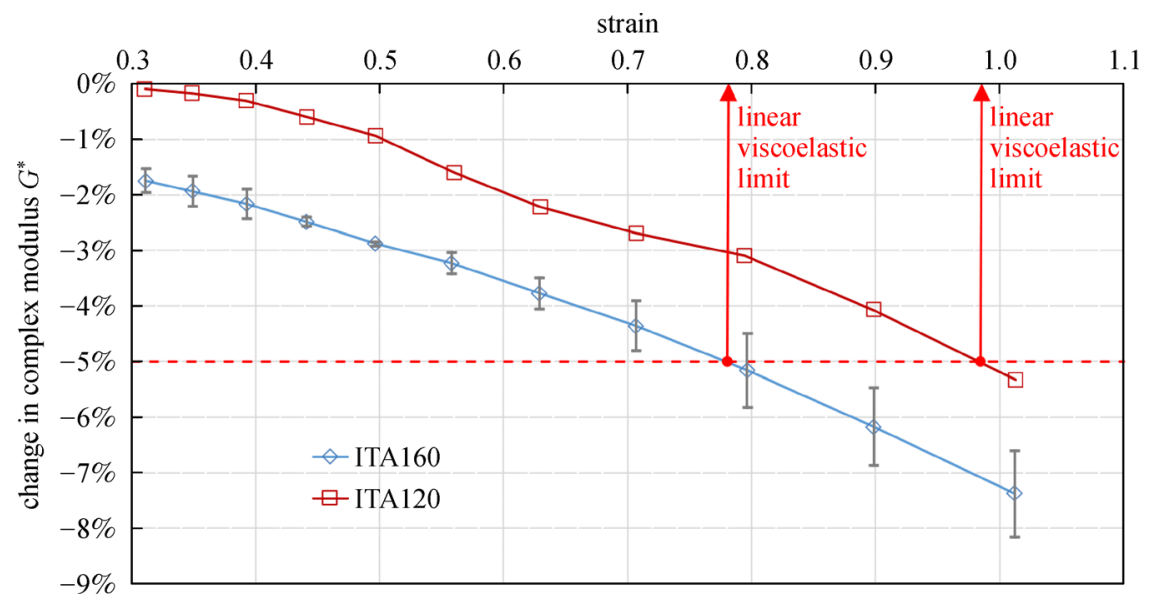

Fig. 6 Determination of the limits of the linear viscoelastic region (error bars represent maximum and minimum values). 
3.3 Complex modulus, phase angle and derivative parameters

In this section, the discussion on the rheological properties of PMB focuses on the low complex modulus range, that is, $G^{*}$ at approximately $5 \mathrm{kPa}$ and lower. This is because previous studies $[21,22]$ showed that PMB rheology tends to be more sensitive to morphology in this range. Tables 1 and 2 present the DSR measurement results of the complex modulus $G^{*}$ and phase angle $\delta$ at different test temperatures and angular frequencies, as well as their derivative parameters (including $G^{*} / \sin \delta$, elastic modulus $G^{\prime}$, and $\left.G^{*} /(1-(1 /(\tan \delta \cdot \sin \delta)))\right)$.

The performance grade (PG) high-temperature parameter $G^{*} / \sin \delta$ was derived from the loss compliance $J^{\prime \prime}$ to limit the non-recoverable strain [39]. However, this parameter was found to be inadequate for describing and predicting the resistance of PMB to permanent deformation [40]. As a refinement, Shenoy [41-43] suggested the parameter $G^{*} /(1-(1 /(\tan \delta \cdot \sin \delta)))$, which was claimed to be more sensitive to elastic behavior than $G^{*} / \sin \delta$ and could thus more accurately represent PMB responses. However, the form of Shenoy's parameter does not allow its use for $\delta$ values below $52^{\circ}$, because it would lead to unrealistic negative results. For this study, nevertheless, it is a suitable parameter to be analyzed, as this study focuses on the low complex modulus range in which the $\delta$ values are greater than $52^{\circ}$.

As in Table 1, both ITA160 and ITA120 had a complex modulus $G^{*}$ value of approximately $5100 \mathrm{~Pa}$ at $64^{\circ} \mathrm{C}$ and $10 \mathrm{rad} / \mathrm{s}$. This is approximately the same level as the $G_{0}^{*}$ value determined by the strain sweep in Fig. 5, confirming the good reproducibility of the results. At 10 $\mathrm{rad} / \mathrm{s}$, the DSR measurement results indicate that ITA160

Table 1 Test results of complex modulus $G^{*}$ and phase angle $\delta$

\begin{tabular}{|c|c|c|c|c|c|}
\hline \multirow[t]{2}{*}{ angular frequency (rad/s) } & \multirow[t]{2}{*}{ test temperature $\left({ }^{\circ} \mathrm{C}\right)$} & \multicolumn{2}{|c|}{ complex modulus $G^{*}(\mathrm{~Pa})$} & \multicolumn{2}{|c|}{ phase angle $\delta\left(^{\circ}\right)$} \\
\hline & & ITA160 & ITA120 & ITA160 & ITA120 \\
\hline \multirow[t]{4}{*}{$\overline{10}$} & 64 & $5.10 \times 10^{3}$ & $5.12 \times 10^{3}$ & 73.7 & 73.8 \\
\hline & 70 & $2.46 \times 10^{3}$ & $2.64 \times 10^{3}$ & 74.7 & 75.4 \\
\hline & 76 & $1.35 \times 10^{3}$ & $1.47 \times 10^{3}$ & 75.2 & 76.7 \\
\hline & 82 & $7.25 \times 10^{2}$ & $8.42 \times 10^{2}$ & 74.6 & 77.7 \\
\hline \multirow[t]{4}{*}{1} & 64 & $7.60 \times 10^{2}$ & $6.27 \times 10^{2}$ & 74.8 & 77.0 \\
\hline & 70 & $4.21 \times 10^{2}$ & $3.17 \times 10^{2}$ & 76.6 & 75.2 \\
\hline & 76 & $3.04 \times 10^{2}$ & $1.67 \times 10^{2}$ & 63.8 & 77.5 \\
\hline & 82 & $1.64 \times 10^{2}$ & $1.16 \times 10^{2}$ & 66.8 & 86.0 \\
\hline \multirow[t]{4}{*}{0.1} & 64 & $1.06 \times 10^{2}$ & $8.66 \times 10^{1}$ & 71.0 & 76.6 \\
\hline & 70 & $7.97 \times 10^{1}$ & $4.22 \times 10^{1}$ & 77.3 & 72.1 \\
\hline & 76 & $3.20 \times 10^{1}$ & $2.37 \times 10^{1}$ & 73.7 & 81.1 \\
\hline & 82 & $1.64 \times 10^{1}$ & $1.20 \times 10^{1}$ & 76.1 & 81.4 \\
\hline
\end{tabular}

Table 2 Test results of derivative parameters based on complex modulus $G^{*}$ and phase angle $\delta$

\begin{tabular}{|c|c|c|c|c|c|c|c|}
\hline \multirow{2}{*}{$\begin{array}{l}\text { angular } \\
\text { frequency } \\
(\mathrm{rad} / \mathrm{s})\end{array}$} & \multirow[t]{2}{*}{ test temperature $\left({ }^{\circ} \mathrm{C}\right)$} & \multicolumn{2}{|c|}{$G^{*} / \sin \delta(\mathrm{Pa})$} & \multicolumn{2}{|c|}{ elastic modulus $G^{\prime}(\mathrm{Pa})$} & \multicolumn{2}{|c|}{$G^{*} /(1-(1 /(\tan \delta \cdot \sin \delta)))(\mathrm{Pa})$} \\
\hline & & ITA160 & ITA120 & ITA160 & ITA120 & ITA160 & ITA120 \\
\hline \multirow[t]{4}{*}{10} & 64 & $5.31 \times 10^{3}$ & $5.33 \times 10^{3}$ & $1.43 \times 10^{3}$ & $1.43 \times 10^{3}$ & $7.33 \times 10^{3}$ & $7.34 \times 10^{3}$ \\
\hline & 70 & $2.55 \times 10^{3}$ & $2.73 \times 10^{3}$ & $6.49 \times 10^{2}$ & $6.67 \times 10^{2}$ & $3.43 \times 10^{3}$ & $3.61 \times 10^{3}$ \\
\hline & 76 & $1.40 \times 10^{3}$ & $1.51 \times 10^{3}$ & $3.45 \times 10^{2}$ & $3.38 \times 10^{2}$ & $1.86 \times 10^{3}$ & $1.94 \times 10^{3}$ \\
\hline & 82 & $7.52 \times 10^{2}$ & $8.62 \times 10^{2}$ & $1.92 \times 10^{2}$ & $1.79 \times 10^{2}$ & $1.01 \times 10^{3}$ & $1.08 \times 10^{3}$ \\
\hline \multirow[t]{4}{*}{1} & 64 & $7.87 \times 10^{2}$ & $6.44 \times 10^{2}$ & $1.99 \times 10^{2}$ & $1.41 \times 10^{2}$ & $1.06 \times 10^{3}$ & $8.22 \times 10^{2}$ \\
\hline & 70 & $4.33 \times 10^{2}$ & $3.28 \times 10^{2}$ & $9.75 \times 10^{1}$ & $8.11 \times 10^{1}$ & $5.58 \times 10^{2}$ & $4.36 \times 10^{2}$ \\
\hline & 76 & $3.38 \times 10^{2}$ & $1.71 \times 10^{2}$ & $1.34 \times 10^{2}$ & $3.62 \times 10^{1}$ & $6.73 \times 10^{2}$ & $2.16 \times 10^{2}$ \\
\hline & 82 & $1.78 \times 10^{2}$ & $1.16 \times 10^{2}$ & $6.45 \times 10^{1}$ & $7.96 \times 10^{0}$ & $3.07 \times 10^{2}$ & $1.25 \times 10^{2}$ \\
\hline \multirow[t]{4}{*}{0.1} & 64 & $1.12 \times 10^{2}$ & $8.90 \times 10^{1}$ & $3.45 \times 10^{1}$ & $2.01 \times 10^{1}$ & $1.67 \times 10^{2}$ & $1.15 \times 10^{2}$ \\
\hline & 70 & $8.17 \times 10^{1}$ & $4.43 \times 10^{1}$ & $1.75 \times 10^{1}$ & $1.29 \times 10^{1}$ & $1.04 \times 10^{2}$ & $6.39 \times 10^{1}$ \\
\hline & 76 & $3.34 \times 10^{1}$ & $2.40 \times 10^{1}$ & $8.97 \times 10^{0}$ & $3.67 \times 10^{0}$ & $4.60 \times 10^{1}$ & $2.82 \times 10^{1}$ \\
\hline & 82 & $1.69 \times 10^{1}$ & $1.21 \times 10^{1}$ & $3.95 \times 10^{0}$ & $1.80 \times 10^{0}$ & $2.20 \times 10^{1}$ & $1.42 \times 10^{1}$ \\
\hline
\end{tabular}


and ITA120 only differ to a limited extent. According to the test results in Table 2, both samples fulfilled the $1.00 \times$ $10^{3} \mathrm{~Pa}$ PG criterion of $G^{*} / \sin \delta$ for the original binder at $76^{\circ} \mathrm{C}$ (ASTM D6373). Likewise, with Shenoy's parameter $G^{*} /(1-(1 /(\tan \delta \cdot \sin \delta)))$, the samples both passed $1.00 \times$ $10^{3} \mathrm{~Pa}$ even at $82^{\circ} \mathrm{C}$.

As the angular frequency decreases, however, $G^{*}$ decreases to below $1000 \mathrm{~Pa}$, and the difference between ITA160 and ITA120 becomes significant, particularly in terms of $\delta$ and $G^{\prime}$. The phase angle of ITA160 decreased to $63.8^{\circ}$ at $76^{\circ} \mathrm{C}$ and $1 \mathrm{rad} / \mathrm{s}$, whereas that of ITA 120 was $77.5^{\circ}$. At $64^{\circ} \mathrm{C}$ and $1 \mathrm{rad} / \mathrm{s}$, the $G^{*} /(1-(1 /(\tan \delta \cdot \sin \delta)))$ value of ITA160 exceeded $1.00 \times 10^{3} \mathrm{~Pa}$, but that of ITA120 was below this value. Soenen et al. [19,20] observed similar effects, that is, the influence of the thermal history on the rheological measurements is more significant at lower frequencies.

This transition of significance between frequencies can be related to the difference in morphology between the two PMB samples. In comparison with the two-phase morphology of ITA120, the uniform one-phase microstructure of ITA 160 may not make a significant difference at $10 \mathrm{rad} / \mathrm{s}$ (ITA120 was slightly stiffer and more viscous). However, at lower angular frequencies, the stiffness and elasticity of ITA160 became greater than that of ITA120. The lower frequencies also resulted in an increase in the stored (decrease in the dissipated) energy for ITA160 during the shear cycles [44-46]. This means that, assuming that the traffic is slow moving at high temperatures, SBS-modified bitumen with superior polymer-bitumen miscibility (i.e., more likely to present a homogenous morphology) would provide higher resistance to traffic loading in terms of permanent deformation. Appropriate handling of PMB during the construction process, in contrast to poor handling that leads to massive phase separation and evolution, would have a similar influence, and thus could contribute to improving the resistance of the binder to permanent deformation under certain extreme conditions.

\subsection{Low shear viscosity}

Zero shear viscosity (ZSV) of bituminous binders has been studied for a long time as a potential indicator of permanent deformation. It aims to remove the possible influences of the dependency of the viscoelastic response on the loading frequency, especially for pseudoplastic PMB with delayed elasticity [29,30]. Several test methods can be used to determine the ZSV value, including creep tests and frequency sweep tests. The latter method was used in this study, and the Cross model [47] was employed to extrapolate the results to lower frequencies. However, for certain PMB variants (and unmodified bitumen at lower temperatures), extrapolation can lead to unreliable results. This is because the extrapolated curve may not present a plateau at very low frequencies but can be curvilinear in many cases. Thus, the common practice for studying PMB is to determine the LSV at a relatively low frequency instead [48-50], for example at $0.001 \mathrm{~Hz}$ (approximately $0.006 \mathrm{rad} / \mathrm{s}$ ), which was used in previous studies [30,31].

The four-parameter Cross model [51] can be written as

$$
\frac{\eta^{*}(\omega)-\eta_{\infty}^{*}}{\eta_{0}^{*}-\eta_{\infty}^{*}}=\frac{1}{1+(K \omega)^{m}} .
$$

In Eq. (5), $\eta^{*}(\omega)$ is the complex viscosity, $\eta_{\infty}^{*}$ is the limiting viscosity at very high frequencies (the other Newtonian region), $\eta_{0}^{*}$ is the ZSV, $\omega$ is the angular frequency, and $K$ and $m$ are model constants. Assuming $\eta^{*}(\omega)>>\eta_{\infty}^{*}$ for the investigated frequency range [52], the four-parameter Cross model can be simplified as

$$
\eta^{*}(\omega)=\frac{\eta_{0}^{*}}{1+(K \omega)^{m}} .
$$

Based on Eq. (6), the obtained complex viscosity results from the frequency sweep were fitted and extrapolated to $0.001 \mathrm{rad} / \mathrm{s}$, as shown in Fig. 7. The extrapolated complex viscosity at $0.006 \mathrm{rad} / \mathrm{s}$ was taken as the LSV value and is listed in Table 3. The results indicate that the two samples cross each other at all three studied temperatures. At higher frequencies, the difference between the samples was limited (ITA120 had slightly higher values). However, as the frequency decreased, the complex viscosity of ITA 160 continued to increase, whereas that of ITA120 stabilized. Thus, more significant differences were observed at the lower frequencies. Similar phenomena were also observed by Soenen et al. $[19,20]$. This trend agrees well with the complex modulus results discussed in the previous section and, in a similar way, can be related to the difference in morphology between the two PMB samples.

The results in Table 3 indicate that the LSV values at $0.006 \mathrm{rad} / \mathrm{s}$ of ITA160 are higher than those of ITA120. However, it is worth noting that the absolute difference between the two samples is highly sensitive to the frequency level selected for LSV determination. At a frequency lower than a certain level, the LSV might misestimate the permanent deformation potential of the PMB $[53,54]$. The sensitivity to the selected frequency also depends on the test temperature. As the test temperature increased, the crossover of the two samples moved toward a higher frequency. This shift in the crossover may disclose (possibly result from) certain intrinsic properties of the PMB microstructures.

\subsection{Multiple stress creep and recovery}

MSCR is a relatively new test method for characterizing the high-temperature rheological properties of bituminous binders. In the standard protocol ASTM D7405 (version 10a), or alternatively EN 16659 (version 2016), a sample is tested at two stress levels (100 $\mathrm{Pa}$ and $3200 \mathrm{~Pa}$ ) without a rest period in between. For data measurement and analysis, ten repetitive creep-recovery cycles were run at each stress 


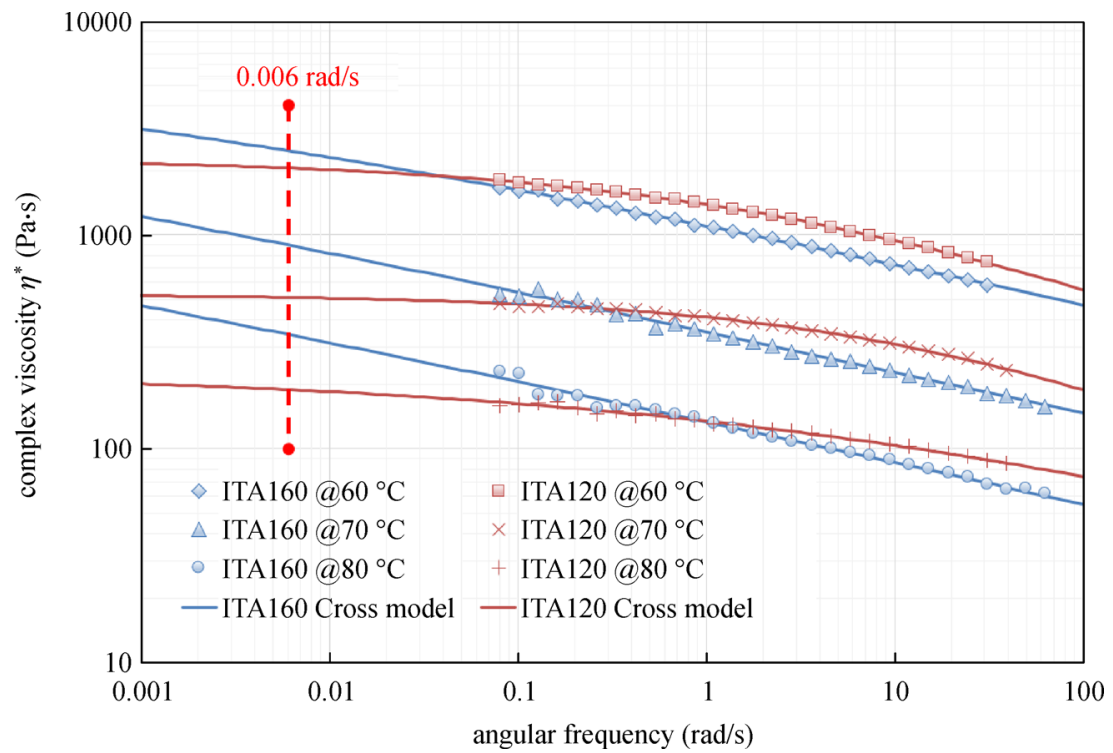

Fig. 7 Fitting and extrapolation with the Cross model.

Table 3 Low shear viscosity at $0.006 \mathrm{rad} / \mathrm{s}$ (approximately $0.001 \mathrm{~Hz}$ )

\begin{tabular}{|c|c|c|c|c|c|c|}
\hline \multirow[t]{2}{*}{ test } & \multicolumn{2}{|c|}{ @ $60^{\circ} \mathrm{C}$} & \multicolumn{2}{|c|}{ (a) $70^{\circ} \mathrm{C}$} & \multicolumn{2}{|c|}{ (a) $80^{\circ} \mathrm{C}$} \\
\hline & ITA160 & ITA120 & ITA160 & ITA120 & ITA160 & ITA120 \\
\hline $\begin{array}{l}\text { low shear viscosity } \\
(\mathrm{Pa} \cdot \mathrm{s}) @ 0.006 \mathrm{rad} / \mathrm{s}\end{array}$ & 2484 & 2061 & 898 & 512 & 343 & 189 \\
\hline
\end{tabular}

level, although ten additional cycles would be necessary at $100 \mathrm{~Pa}$ to preload the sample according to the latest version (15 or later) of ASTM D7405. Each creep-recovery cycle includes a creep period (constant stress) of $1 \mathrm{~s}$ and a recovery period (zero stress) of $9 \mathrm{~s}$. The total strain of each cycle consists of a recoverable portion and an unrecoverable portion. The elastic recovery and final residual strain are measures of the binder performance. Figure 8 shows the MSCR test results of ITA160 and ITA120 at different temperatures (without pre-loading). The results indicate that ITA120 experienced higher accumulated strain than ITA160 at all tested temperatures. The strain recovery percentage was rather low at $76^{\circ} \mathrm{C}$ for both samples, leading to a relatively small difference between them. However, at lower temperatures, the percentage of strain recovery increased. The difference between the two samples also increased (relative to the total amount of accumulated strain), particularly at $3200 \mathrm{~Pa}$.

Using the MSCR test results, the average percent recovery $R$ and non-recoverable creep compliance $J_{\mathrm{nr}}$ of

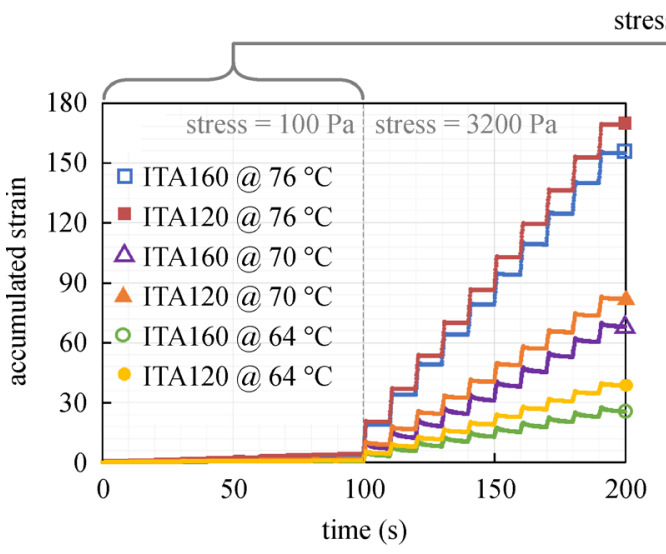

(a)

ess $=100 \mathrm{~Pa}$

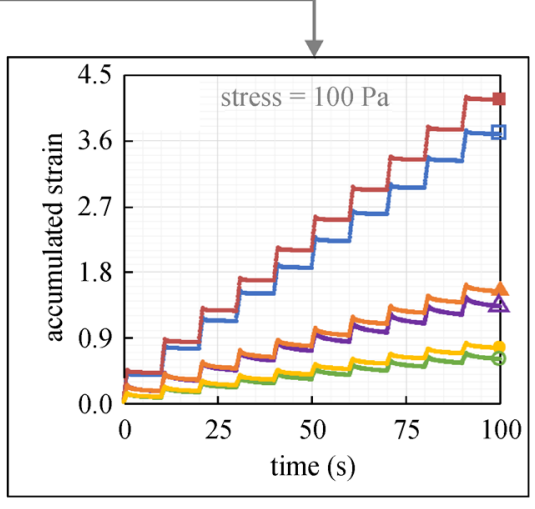

(b)

Fig. 8 Multiple stress creep and recovery results: (a) both stress levels and (b) stress at $100 \mathrm{~Pa}$ only. 
the ten repetitive creep-recovery cycles were determined at both stress levels. The $R$-value represents the recoverable elastic strain (including the delayed) as a percentage, whereas $J_{\mathrm{nr}}$ is a measure of the residual strain due to permanent deformation [55]. Additionally, the percent difference values $R_{\text {diff }}$ and $J_{\text {nr-diff }}$ between stress levels can be used to characterize the stress sensitivity of the sample [56]. In this study, the average total strain $\varepsilon_{1}$ (at the end of the creep period) of the ten repetitive creep-recovery cycles was also analyzed for both stress levels. The parameters of ITA160 and ITA120 are presented in Fig. 9.

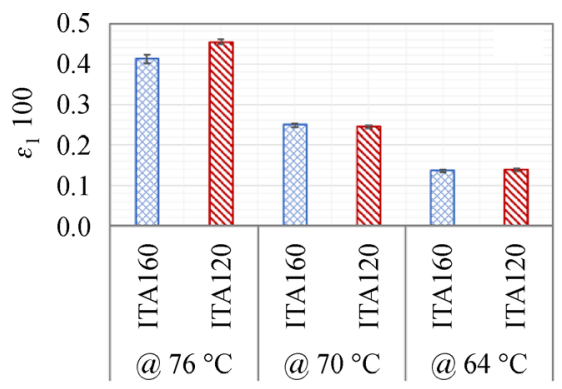

(a)

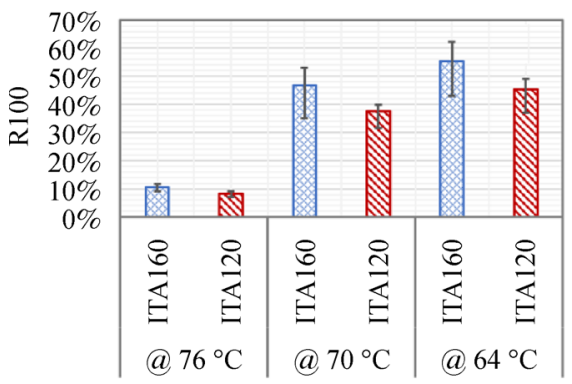

(c)

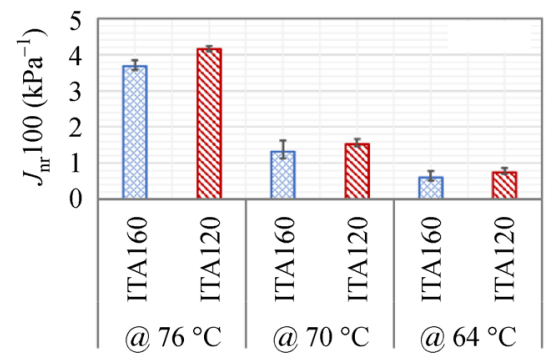

(e)

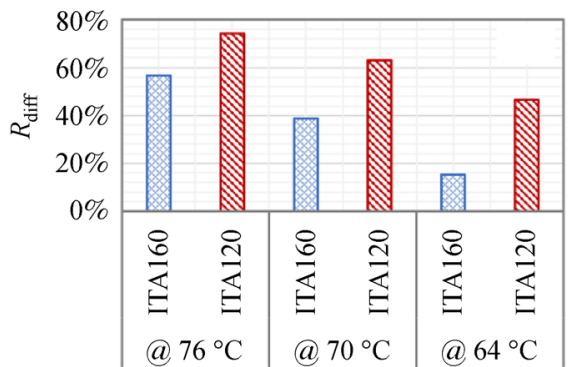

(g)
As shown in Figs. 9(a) and 9(b), the values of the total strain $\varepsilon_{1}$ of ITA160 and ITA120 were quite similar at both stress levels and all the tested temperatures. However, sample ITA160, which was conditioned at a higher temperature, had higher strain recovery (Figs. 9(c) and 9(d)). This discloses that, rather than thermo-oxidative aging during conditioning, the difference in their morphology was responsible for the different high-temperature properties of the samples. In comparison with the twophase morphology of ITA120, the uniform one-phase microstructure of ITA160 enabled a greater extent of

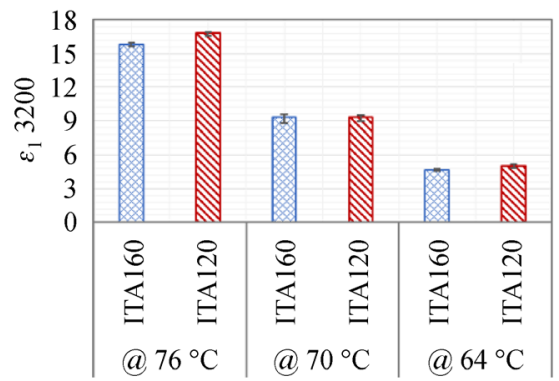

(b)

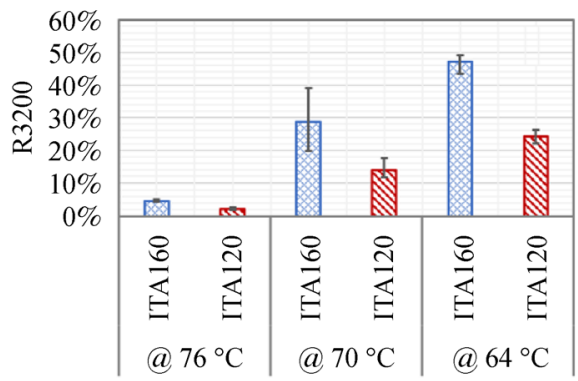

(d)

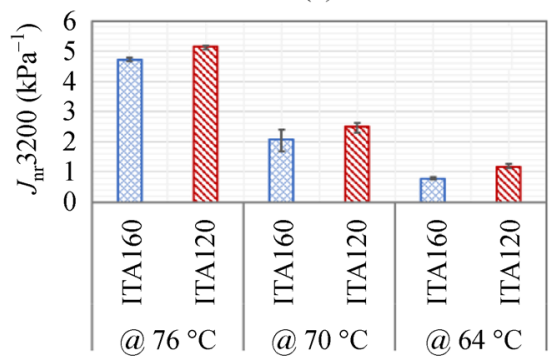

(f)

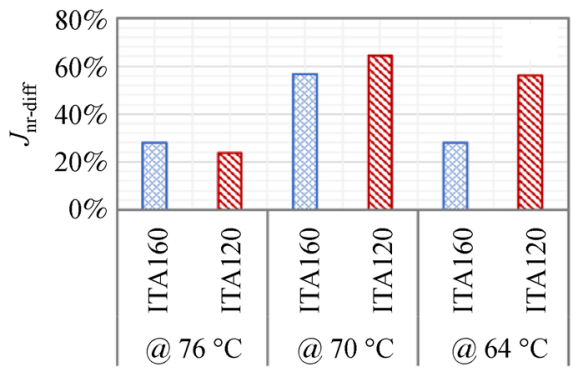

(h)

Fig. 9 Average MSCR parameters of ten repetitive creep-recovery cycles (error bars represent the maximum and minimum values): (a) total strain $\varepsilon_{1}$ at $100 \mathrm{~Pa}$ stress; (b) total strain $\varepsilon_{1}$ at $3200 \mathrm{~Pa}$ stress; (c) percent recovery $R$ at $100 \mathrm{~Pa}$ stress; (d) percent recovery $R$ at $3200 \mathrm{~Pa}$ stress; (e) non-recoverable creep compliance $J_{\text {nr }}$ at 100 Pa stress; (f) non-recoverable creep compliance $J_{\text {nr }}$ at 3200 Pa stress; (g) percent difference in $R$ between stress levels, $R_{\text {diff }}$; (h) percent difference in $J_{\mathrm{nr}}$ between stress levels, $J_{\mathrm{nr}-\mathrm{diff}}$. 
elastic recovery after the creep period. Similar conclusions were also drawn by Król et al. [57] for two-phase PMB samples with varying microstructures.

The results in Figs. 9(e) and 9(f) indicate that ITA160 had lower $J_{\text {nr }}$ values and could thus provide a higher resistance to permanent deformation than ITA120. In addition, according to Figs. 9(g) and 9(h), the percent differences in $R$ and $J_{\mathrm{nr}}$ between the two applied stress levels $(100$ and $3200 \mathrm{~Pa})$ were generally lower for the uniform one-phase PMB microstructure, suggesting a lower sensitivity to stress change in the tested range. These results imply that, to a certain extent, SBS-modified bitumen with improved polymer-bitumen miscibility (more likely to present homogenous morphology) would be more resistant to heavy vehicular traffic in terms of permanent deformation. Similarly, appropriate handling of PMB during the construction process that results in limited phase separation and evolution, would have the same effect.

\subsection{Discussion: Influence of morphology}

Based on the test results and discussion in previous sections, it can be concluded that, to a considerable extent, the microstructure of PMB affects its rheological properties in the high-temperature range, despite the varying significance at various temperatures or frequencies. Within the range tested in this study, however, the influence of the microstructure of SBS-modified bitumen displays a certain tendency. Because the PMB morphology was quantitatively evaluated in this study, it is possible to analyze the aforementioned tendency on a quantitative basis. Table 4 lists the 2D-FFT analysis results $(\xi)$ of the PMB microstructures and selected parameters by rheological testing, including the LVE region limit, phase angle, $G^{\prime}$, LSV, and percent recovery by MSCR.

At high temperatures, as the base bitumen (in fact, the bitumen-rich phase or so-called "residual") softens, the polymer-rich phase starts to play a more dominant role in PMB. The distribution pattern of the polymer-rich phase in the PMB, that is, the morphology, begins to have a greater impact. In comparison with the two-phase morphology analyzed in this study, the uniform one-phase PMB microstructure $(\xi=0 \mathrm{~mm})$ with the SBS copolymer tended to narrow its LVE region (Table 4). Within the LVE region, especially at low frequencies, the homogenous SBSmodified bitumen was more elastic and capable of storing more energy during loading. This increased the values of the indicators for permanent deformation resistance (more resistant). On the other hand, the homogenous morphology could assist in achieving higher strain recovery after traffic loading outside the LVE region.

The number of samples analyzed in this study was limited. Thus, the discussion on the relationship between the PMB morphology and rheology is preliminary and, so far, only applicable to SBS-modified bitumen within the analyzed range of temperatures and frequencies. More measurements with additional samples might lead to an empirical regression relation, but such a relationship would have only material-specific validity and would have limited potential for generalization to other modified binders. An alternative approach is morphology-based micromechanical modeling. Based on the findings of this study, the characteristic wavelength $\xi$ of the PMB morphology would have to be considered in the micromechanical models. To supplement the previously reported models based on the Kerner model [58] or the general selfconsistent model [59], a general relationship for the PMB can be written as

$$
p=f\left(p_{\mathrm{b}}, p_{\mathrm{p}}, \phi, \xi\right),
$$

where $p$ is the PMB property of interest. It can be considered as a function of the related property of the base bitumen $\left(p_{\mathrm{b}}\right)$, property of the pure polymer modifier $\left(p_{\mathrm{p}}\right)$, the polymer fraction $\phi$, and the characteristic wavelength $\xi$ of the PMB morphology.

Furthermore, it is worth noting that this study aims to investigate the effect of PMB morphology ( $\xi$ varying) on its rheology with the same material composition (constant $p_{\mathrm{b}}, p_{\mathrm{p}}$, and $\left.\phi\right)$. The morphology of the PMB can change significantly during transport, storage, mixing, paving, and compaction processes, owing to the complex thermal conditions. Thus, the above-discussed tendency of the influence of the morphology can help to provide an understanding of the importance of maintaining stable and appropriate processes for binder handling and the construction of roads with excellent performance. However, when deciding whether to use PMB or which PMB to use, the effects of the varying properties of the raw materials, including base bitumen and pure polymer modifier, as well as the polymer content, should be considered in addition to the effects of morphology that may vary.

\section{Conclusions}

Using the same raw materials and formulation, the effects

Table 4 Effect of morphology on the rheology of SBS-modified bitumen

\begin{tabular}{|c|c|c|c|c|c|c|}
\hline sample & $\begin{array}{c}\text { characteristic } \\
\text { wavelength } \xi(\mathrm{mm})\end{array}$ & $\begin{array}{l}\text { LVE limit (strain) } \\
@ 64^{\circ} \mathrm{C} \text { and } 10 \mathrm{rad} / \mathrm{s}\end{array}$ & $\begin{array}{l}\text { phase angle } \delta\left(^{\circ}\right) \\
@ 76^{\circ} \mathrm{C} \text { and } 1 \mathrm{rad} / \mathrm{s}\end{array}$ & $\begin{array}{c}\text { elastic modulus } G^{\prime}(\mathrm{Pa}) \\
@ 76^{\circ} \mathrm{C} \text { and } 1 \mathrm{rad} / \mathrm{s}\end{array}$ & $\begin{array}{c}\mathrm{LSV}(\mathrm{Pa} \cdot \mathrm{s}) \\
@ 70^{\circ} \mathrm{C} \text { and } 0.006 \mathrm{rad} / \mathrm{s}\end{array}$ & $\mathrm{R} 3200 @ 70^{\circ} \mathrm{C}$ \\
\hline ITA160 & 0 & 0.778 & 63.8 & $1.34 \times 10^{2}$ & 898 & $28.8 \%$ \\
\hline ITA120 & 2.356 & 0.983 & 77.5 & $3.62 \times 10^{1}$ & 512 & $13.9 \%$ \\
\hline
\end{tabular}


of the morphology on the rheological properties of SBSmodified bitumen were investigated within the hightemperature range in this study. The microstructures of the PMB samples were quantitatively evaluated using the 2D-FFT method. Various rheological parameters, including the limits of the LVE region, complex modulus, phase angle, derivative parameters, and LSV, were measured using DSR. MSCR tests were performed at high temperatures. Based on the above-described results and discussion, the following conclusions can be drawn.

1) The 2D-FFT method was successfully applied to quantitatively evaluate the PMB microstructure. Analysis of fluorescence microscopy images indicated that conditioning by isothermal annealing at $160^{\circ} \mathrm{C}$ and $120^{\circ} \mathrm{C}$ led to an evident difference in the PMB microstructure between ITA160 and ITA120. It is demonstrated that varying the thermal history is a practical way to vary the PMB morphology with the same raw materials and formulation.

2) In comparison with the two-phase morphology of ITA120, the uniform one-phase microstructure of ITA160 with the SBS copolymer tended to cause its LVE region to become narrower because of the dominant polymer matrix (characteristic wavelength $\xi=0 \mathrm{~mm}$ ). This reduction in the strain limit can be considered as an indication of a higher degree of polymer-bitumen interaction in ITA160.

3) Within the LVE region, the homogenous PMB morphology with the SBS copolymer might not significantly differ from the binary droplet-in-matrix one at certain frequencies, for example, $10 \mathrm{rad} / \mathrm{s}$. However, at lower frequencies, ITA160 could store more energy during shear cycles and remain more elastic than ITA120. This may imply that ITA160 has a higher resistance to permanent deformation resulting from slow traffic loading at high temperatures.

4) According to the MSCR test results, especially at $3200 \mathrm{~Pa}$ stress, ITA160 reached a higher strain recovery after creep loading and ultimately had lower residual strain. Thus, ITA160 could also offer higher resistance to permanent deformation than ITA120 outside the LVE region. This result indicates that, to a certain extent, SBSmodified bitumen with superior polymer-bitumen miscibility (more likely to present a homogenous morphology) would be more resistant to heavy traffic in terms of permanent deformation. Similar effects are expected by appropriate handling of the PMB during the construction process, which is likely to lead to limited phase separation and evolution.

5) The analyses presented in this paper show the significance of the characteristic wavelength $\xi$ of the PMB morphology for high-temperature rheology. This suggests that this microstructural parameter should be considered for the morphology-based micromechanical modeling of $\mathrm{PMB}$, in addition to the base bitumen property, pure polymer modifier property, and polymer fraction in the PMB.
Acknowledgements This study was conducted with funding from Trafikverket (Swedish Transport Administration) through the BVFF (Bana Väg för Framtiden) program. The financial support is gratefully acknowledged.

Funding note: Open access funding provided by the Swedish National Road and Transport Research Institute (VTI)

Open Access This article is licensed under a Creative Commons Attribution 4.0 International License (https://creativecommons.org/licenses/ by/4.0/), which permits use, sharing, adaptation, distribution and reproduction in any medium or format, as long as you give appropriate credit to the original author(s) and the source, provide a link to the Creative Commons licence, and indicate if changes were made. The images or other third party material in this article are included in the article's Creative Commons licence, unless indicated otherwise in a credit line to the material. If material is not included in the article's Creative Commons licence and your intended use is not permitted by statutory regulation or exceeds the permitted use, you will need to obtain permission directly from the copyright holder. To view a copy of this licence, visit http://creativecommons.org/licenses/by/4.0/.

\section{References}

1. Lu X, Isacsson U. Rheological characterization of styrenebutadiene-styrene copolymer modified bitumens. Construction \& Building Materials, 1997, 11(1): 23-32

2. Airey G D. Rheological properties of styrene butadiene styrene polymer modified road bitumens. Fuel, 2003, 82(14): 1709-1719

3. Adedeji A, Grünfelder T, Bates F S, Macosko C W, Stroup-Gardiner M, Newcomb D E. Asphalt modified by SBS triblock copolymer: Structures and properties. Polymer Engineering and Science, 1996, 36(12): 1707-1723

4. Lesueur D, Gérard J F, Claudy P, Létoffé J M, Martin D, Planche J P. Polymer modified asphalts as viscoelastic emulsions. Journal of Rheology (New York, N.Y.), 1998, 42(5): 1059-1074

5. Lu X, Isacsson U. Modification of road bitumens with thermoplastic polymers. Polymer Testing, 2000, 20(1): 77-86

6. Yildirim Y. Polymer modified asphalt binders. Construction \& Building Materials, 2007, 21(1): 66-72

7. Sengoz B, Isikyakar G. Evaluation of the properties and microstructure of SBS and EVA polymer modified bitumen. Construction \& Building Materials, 2008, 22(9): 1897-1905

8. Wu S, Pang L, Mo L, Chen Y, Zhu G. Influence of aging on the evolution of structure, morphology and rheology of base and SBS modified bitumen. Construction \& Building Materials, 2009, 23(2): 1005-1010

9. Polacco G, Filippi S, Merusi F, Stastna G. A review of the fundamentals of polymer-modified asphalts: Asphalt/polymer interactions and principles of compatibility. Advances in Colloid and Interface Science, 2015, 224: 72-112

10. Laukkanen O V, Soenen H, Winter H H, Seppälä J. Lowtemperature rheological and morphological characterization of SBS modified bitumen. Construction \& Building Materials, 2018, 179: $348-359$

11. Zhu J, Balieu R, Wang $H$. The use of solubility parameters and free energy theory for phase behaviour of polymer-modified bitumen: A review. Road Materials and Pavement Design, 2021, 22(4): 757-778

12. Pérez-Lepe A, Martínez-Boza F J, Gallegos C, González O, Muñoz 
M E, Santamaría A. Influence of the processing conditions on the rheological behaviour of polymer-modified bitumen. Fuel, 2003, 82(11): 1339-1348

13. Mouillet V, Lamontagne J, Durrieu F, Planche J P, Lapalu L. Infrared microscopy investigation of oxidation and phase evolution in bitumen modified with polymers. Fuel, 2008, 87(7): 1270-1280

14. Xia T, Xu J, Huang T, He J, Zhang Y, Guo J, Li Y. Viscoelastic phase behavior in SBS modified bitumen studied by morphology evolution and viscoelasticity change. Construction \& Building Materials, 2016, 105: 589-594

15. Zhu J, Balieu R, Lu X, Kringos N. Microstructure evaluation of polymer-modified bitumen by image analysis using two-dimensional fast Fourier transform. Materials \& Design, 2018, 137: 164175

16. Zhu J, Lu X, Kringos N. Experimental investigation on storage stability and phase separation behaviour of polymer-modified bitumen. International Journal of Pavement Engineering, 2018, 19(9): 832-841

17. Liang $M$, Xin X, Fan W, Wang H, Ren S, Shi J. Effects of polymerized sulfur on rheological properties, morphology and stability of SBS modified asphalt. Construction \& Building Materials, 2017, 150: 860-871

18. Wang $\mathrm{P}$, Dong Z, Tan Y, Liu Z. Identifying the rheological properties of polymer-modified bitumen based on its morphology. Road Materials and Pavement Design, 2017, 18(sup3): 249-258

19. Soenen H, De Visscher J, Vanelstraete A, Redelius P. The influence of thermal history on binder rutting indicators. Road Materials and Pavement Design, 2005, 6(2): 217-238

20. Soenen H, De Visscher J, Vanelstraete A, Redelius P. Influence of thermal history on rheological properties of various bitumen. Rheologica Acta, 2006, 45(5): 729-739

21. Soenen H, Lu X, Redelius P. The morphology of bitumen-SBS blends by UV microscopy: An evaluation of preparation methods. Road Materials and Pavement Design, 2008, 9(1): 97-110

22. Soenen H, Lu X, Redelius P. The morphology of SBS modified bitumen in binders and in asphalt mix. In: Advanced Testing and Characterization of Bituminous Materials: Proceedings of the 7th International RILEM Symposium ATCBM09. Leiden: CRC Press, 2009, 151-160

23. Laukkanen O V, Soenen H. Rheological characterization of wax modified bituminous binders: Effect of specimen preparation and thermal history. Construction \& Building Materials, 2015, 95: 269278

24. Koenders B. Routine testing and mechanical properties of bitumens. In: Hunter R N, Self A, Read J, eds. The Shell Bitumen Handbook. 6th ed. London: Shell International Petroleum Company Ltd, 2015, $87-118$

25. Tanaka H, Hayashi T, Nishi T. Application of digital image analysis to pattern formation in polymer systems. Journal of Applied Physics, 1986, 59(11): 3627-3643

26. Moolman D W, Aldrich C, Van Deventer J S J, Stange W W. Digital image processing as a tool for on-line monitoring of froth in flotation plants. Minerals Engineering, 1994, 7(9): 1149-1164

27. Schneider C A, Rasband W S, Eliceiri K W. NIH Image to ImageJ: 25 years of image analysis. Nature Methods, 2012, 9(7): 671-675

28. Liu Q, Wu S, Liu C, Wang J. Investigation of rheological properties of TPS modified bitumen. Journal of Central South University of Technology, 2008, 15(S1): 118-121

29. Anderson D, Le Hir Y, Planche J P, Martin D, Shenoy A. Zero shear viscosity of asphalt binders. Transportation Research Record: Journal of the Transportation Research Board, 2002, 1810(1): $54-62$

30. de Visscher J, Vanelstraete A. Practical test methods for measuring the zero shear viscosity of bituminous binders. Materials and Structures, 2004, 37(5): 360-364

31. Morea F, Agnusdei J O, Zerbino R. Comparison of methods for measuring zero shear viscosity in asphalts. Materials and Structures, 2010, 43(4): 499-507

32. Lu X, Soenen H, Redelius P. SBS modified bitumens: Does their morphology and storage stability influence asphalt mix performance? In: Proceedings of the 11th International Conference on Asphalt Pavements. Lino Lakes: ISAP, 2010, 1604-1613

33. Zhu J, Balieu R, Lu X, Kringos N. Numerical investigation on phase separation in polymer-modified bitumen: Effect of thermal condition. Journal of Materials Science, 2017, 52(11): 6525-6541

34. Petersen J C, Robertson R E, Branthaver J F, Harnsberger P M, Duvall J J, Kim S S, Anderson D A, Christiansen D W, Bahia H U, Dongre R, Antle C E, Sharma M G, Button J W, Glover C J. Binder Characterization and Evaluation: Volume 4: Test Method. Strategic Highway Research Program Report No.: SHRP-A-370. 1994

35. Airey G D, Rahimzadeh B, Collop A C. Linear viscoelastic limits of bituminous binders. Electronic Journal of the Association of Asphalt Paving Technologists, 2002, 71: 89-115

36. Airey G, Rahimzadeh B, Collop A. Linear viscoelastic performance of asphaltic materials. Road Materials and Pavement Design, 2003, 4(3): 269-292

37. Airey G D, Rahimzadeh B. Combined bituminous binder and mixture linear rheological properties. Construction \& Building Materials, 2004, 18(7): 535-548

38. Airey G D. Factors affecting the rheology of polymer modified bitumen (PMB). In: McNally T, ed. Polymer Modified Bitumen: Properties and Characterisation. Cambridge: Woodhead Publishing, 2011, 238-263

39. Petersen J C, Robertson R E, Branthaver J F, Harnsberger P M, Duvall J J, Kim S S, Anderson D A, Christiansen D W, Bahia H U. Binder Characterization and Evaluation: Volume 1. Strategic Highway Research Program Report No.: SHRP-A-367. 1994

40. Subhy A. Advanced analytical techniques in fatigue and rutting related characterisations of modified bitumen: Literature review. Construction \& Building Materials, 2017, 156: 28-45

41. Shenoy A. Refinement of the Superpave specification parameter for performance grading of asphalt. Journal of Transportation Engineering, 2001, 127(5): 357-362

42. Shenoy A. Model-fitting the master curves of the dynamic shear rheometer data to extract a rut-controlling term for asphalt pavements. Journal of Testing and Evaluation, 2002, 30(2): 95-102

43. Shenoy A. High temperature performance grading of asphalts through a specification criterion that could capture field performance. Journal of Transportation Engineering, 2004, 130(1): 132137

44. Al-Khateeb G G, Ramadan K Z. Investigation of the effect of rubber on rheological properties of asphalt binders using superpave DSR. 
KSCE Journal of Civil Engineering, 2015, 19(1): 127-135

45. Feng Z, Yu J, Wu S. Rheological evaluation of bitumen containing different ultraviolet absorbers. Construction \& Building Materials, 2012, 29: 591-596

46. Yao H, You Z, Li L, Shi X, Goh S W, Mills-Beale J, Wingard D. Performance of asphalt binder blended with non-modified and polymer-modified nanoclay. Construction \& Building Materials, 2012, 35: 159-170

47. Cross M M. Rheology of non-Newtonian fluids: A new flow equation for pseudoplastic systems. Journal of Colloid Science, 1965, 20(5): 417-437

48. Zoorob S E, Castro-Gomes J P, Pereira Oliveira L A. Assessing low shear viscosity as the new bitumen softening point test. Construction \& Building Materials, 2012, 27(1): 357-367

49. Morea F, Zerbino R, Agnusdei J. Improvements on asphalt mixtures rutting performance characterization by the use of low shear viscosity. Materials and Structures, 2013, 46(1-2): 267-276

50. Morea F, Zerbino R, Agnusdei J. Wheel tracking rutting performance estimation based on bitumen Low Shear Viscosity (LSV), loading and temperature conditions. Materials and Structures, 2014, 47(4): 683-692

51. Sybilski D. Zero-shear viscosity of bituminous binder and its relation to bituminous mixture's rutting resistance. Transportation Research Record: Journal of the Transportation Research Board, 1996, 1535(1): 15-21

52. Zhang H, Chen Z, Xu G, Shi C. Evaluation of aging behaviors of asphalt binders through different rheological indices. Fuel, 2018,
221: 78-88

53. de Visscher J, Vanelstraete A. Equiviscous temperature based on low shear viscosity: Evaluation as binder indicator for rutting and critical discussion of the test procedure. In: Advanced Testing and Characterization of Bituminous Materials: Proceedings of the 7th International RILEM Symposium ATCBM09. Leiden: CRC Press, 2009, 1009-1018

54. Morea F, Agnusdei J O, Zerbino R. The use of asphalt low shear viscosity to predict permanent deformation performance of asphalt concrete. Materials and Structures, 2011, 44(7): 1241-1248

55. Hossain Z, Ghosh D, Zaman M, Hobson K. Use of the multiple stress creep recovery (MSCR) test method to characterize polymermodified asphalt binders. Journal of Testing and Evaluation, 2015, 44(1): 507-520

56. Laukkanen O V, Soenen H, Pellinen T, Heyrman S, Lemoine G. Creep-recovery behavior of bituminous binders and its relation to asphalt mixture rutting. Materials and Structures, 2015, 48(12): 4039-4053

57. Król J, Radziszewski P, Kowalski K J. Influence of microstructural behavior on multiple stress creep recovery (MSCR) in modified bitumen. Procedia Engineering, 2015, 111: 478-484

58. Chen J S, Liao M C, Shiah M S. Asphalt modified by styrenebutadiene-styrene triblock copolymer: Morphology and model. Journal of Materials in Civil Engineering, 2002, 14(3): 224-229

59. Wang H, Liu X, Zhang H, Apostolidis P, Erkens S, Skarpas A. Micromechanical modelling of complex shear modulus of crumb rubber modified bitumen. Materials \& Design, 2020, 188: 108467 